\title{
Riboflavin supplementation in a resettlement village in north-east Thailand
}

\author{
BY D. I. 'THURNHAM,* P. MIGASENA, NIYOMSRI VUDHIVAI \\ AND VENUS SUPAWAN \\ Department of Tropical Nutrition, Faculty of Tropical Medicine, \\ Mahidol University, Bangkok, Thailand \\ (Received I September I97 I - Accepted I3 December I97І)
}

\begin{abstract}
x. A high prevalence of biochemical ariboflavinosis was shown to be present in the preschool children and a small group of adults in a village in north-east Thailand using an in vitro test based on erythrocyte glutathione reductase (EGR) activity.

2. A riboflavin supplement of ro $\mathrm{mg} / \mathrm{d}$ was given to all subjects for $7 \mathrm{~d}$.

3. It was demonstrated that the riboflavin supplement cured the biochemical ariboflavinosis and the results supported the previous suggestion that a stimulation $>20 \%$ of the in vitro EGR activity was a good indicator of ariboflavinosis.

4. A dietary survey carried out on twenty preschool children during the experimental period showed riboflavin intake to be low, $0.18 \pm 0.06 \mathrm{mg} / \mathrm{Mcal}$.

5. No glucose-6-phosphate dehydrogenase (G-6-PD)-deficient subjects were shown to be deficient in ribollavin by the in vitro test. The possibility of using in vivo stimulation of EGR activity by riboflavin is discussed as a possible way of demonstrating ariboflavinosis in G-6PD-deficient subjects.
\end{abstract}

The diet of rural Thai people has been shown to be deficient in riboflavin, and clinical signs commonly associated with ariboflavinosis, glossitis and angular stomatitis have frequently been found (Chandrapond \& Ritchie, 1952; Chandrapond, I955; Hauck \& Sudsaneh, 1959; Interdepartmental Committee on Nutrition for National Defense, 1962). In this department studies were undertaken to investigate the use of the erythrocyte glutathione reductase (EGR) test of Glatzle, Körner, Christeller \& Wiss (1970) to assess biochemically the prevalence of ariboflavinosis. These studies were carricd out in two villages in north-east Thailand, and the prevalence of ariboflavinosis, although fluctuating with the seasons, was generally found to be high (Thurnham, Migasena \& Pavapootanon, I970; Thurnham, Migasena \& Vudhivai, I97 I). A good correlation has been found between the dietary intake of riboflavin and the prevalence of biochemical ariboflavinosis (Thurnham, Migasena, Vudhivai \& Supawan, 197I), but it was considercd that additional evidence, that the EGR test measured ariboflavinosis, would be gained by a supplementation experiment. This was done and the results are reported in this paper.

* Present address: Department of Human Nutrition, London School of Hygiene and Tropical Medicine, Keppel Street (Gower Street), London WCIE 7 HT. 
METHODS

Subjects. The experiment was carried out with preschool children and their parents in a resettlement village in north-east Thailand, in the dry season between February and March r97I.

Blood samples. Blood samples were taken from sixty children and twenty-five parents (Table $\mathrm{r}$ ). Seven of the children were found to be glucose-6-phosphate dehydrogenase (G-6-PD) deficient, but unfortunately the true number of G-6-PD-deficient parents in the initial group is not known as the reagents were not working satisfactorily on the day the parents were examined. Three parents in the sample group, however, were later found to be G-6-PD deficient.

\section{Collection and preservation of haemolysates}

Capillary blood was collected in Unibore heparinized capillary tubes (Harshaw Chemicals Ltd, London) and the packed cells were used to prepare haemolysates as described by Thurnham et al. (r 970). EGR activity was measured in roo $\mu \mathrm{l}$ samples of haemolysate by the method of Glatzle et al. (I970) except that the concentration of reduced nicotinamide adenine-dinucleotide phosphate (NADP) was doubled to 0.4 $\mu \mathrm{mol} /$ cuvette. EGR activity in each haemolysate with and without flavin-adenine dinucleotide (FAD) was measured by observing the decrease of reduced NADP at 334 $\mathrm{nm}$, and the ratio of the stimulated over the basic activity was used to calculate an activation coefficient $(\alpha)$. Enzyme units are expressed as $\mu \mathrm{mol}$ reduced NADP oxidized by EGR in I $\mathrm{ml}$ erythrocytes in Io min at $35^{\circ}$.

Dietary studies. Nine families containing twenty children less than 8 years old were selected randomly from the participants who began the supplementation study. Each family was visited for I full day and the food intake of each child was measured by methods described elsewhere (Thurnham, Pongpaew, Migasena, Supawan and Changbumrung, in preparation).

Riboflavin supplement. Ten tablets, each containing Io mg riboflavin (Atlantic Trading Co. Ltd, Bangkok), were given to each person with the instructions to take one tablet each day for ro d. Each family was visited on the $5_{\text {th }}$ day and then daily until the roth day to check that the instructions were being followed. At least seven tablets were taken during the treatment period by each person included in the results.

G-6-PD deficiency. G-6-PD deficiency was detected by the method of Bernstein (x962).

\section{RESULTS}

\section{Biochemical findings}

It was reported by Flatz (1970) that G-6-PD deficiency may alter the binding properties of EGR for FAD. In view of this, the results obtained for those persons with G-6-PD deficiency are treated separately in this report, but discussion concerning the G-6-PD-deficient subjects will be brief as it is dealt with more fully elsewhere (Thurnham, 1972). 
Table 1. Basic erythrocyte glutathione reductase (EGR) activity, determined in vitro, of haemolysates of preschool children and of their parents before and after receiving a riboflavin supplement

(Mean values and standard deviations; size of group shown in parentheses)

\begin{tabular}{|c|c|c|c|c|}
\hline \multirow{3}{*}{$\begin{array}{l}\text { G-6-PD } \\
\text { status }\end{array}$} & \multicolumn{4}{|c|}{ EGR activity (units†) } \\
\hline & \multicolumn{2}{|c|}{ Children } & \multicolumn{2}{|c|}{ Parents } \\
\hline & Before & After & Before & After \\
\hline \multicolumn{5}{|l|}{ Normal } \\
\hline Whole group & $\begin{array}{c}12 \cdot I \pm 3 \cdot 6 \\
(53)\end{array}$ & - & I I $3 \pm 4 \cdot 3$ & 一 \\
\hline Sample & $\begin{array}{c}12 \cdot 3 \pm 3 \cdot 9 \\
(22)\end{array}$ & $\begin{array}{r}17 \cdot 4 \div 3 \circ \\
(22)^{* * * *}\end{array}$ & $\begin{array}{c}\text { IO. I } \frac{3}{1} 2.9 \\
\text { (IO) }\end{array}$ & $\begin{array}{r}\mathrm{I} 6 \cdot \mathrm{I} \pm 3 \cdot 8 \\
(\mathrm{Io}) * * *\end{array}$ \\
\hline \multicolumn{5}{|l|}{ Deficient } \\
\hline Whole group & $\begin{array}{c}21 \cdot 6 \pm 4 \cdot 0 \\
(7)\end{array}$ & - & 一 & 一 \\
\hline Sample & $20 \cdot 8 \pm 3 \cdot 5$ & $22 \cdot 4 \pm x \cdot 0$ & $20 \cdot 0 \pm 2 \cdot 9$ & $\begin{array}{c}22 \cdot 7 \pm 4 \cdot I \\
(3)\end{array}$ \\
\hline
\end{tabular}

'Sample' refers to those subjects who completed the supplementation experiment, i.e. took at least Io $\mathrm{mg}$ riboflavin/d for $7 \mathrm{~d}$. Differences between the 'sample' and 'whole' groups were not significant.

*** Increase in EGR activity was significant $(P<0.00 \mathrm{I})$ in both children and parents when tested by a test for paired values.

$\dagger \mu$ mol reduced NADP oxidized by EGR in $\mathrm{I} \mathrm{ml}$ erythrocytes in Io min at $35^{\circ}$.

The results in Table I show the mean values of the basic EGR activity before and after riboflavin supplementation. The 'sample' group refers to those children and parents who returned to give a second sample of blood i $5 \mathrm{~d}$ later and who had taken the supplementary riboflavin as directed (see page 92). The values for basic EGR activities of all the sample groups before taking the supplement shown in Table $x$ did not differ significantly from those for the respective whole groups.

After the riboflavin supplement had been taken, the mean values of the basic EGR activities of all sample groups increased (Table r). The increase in EGR activity was inversely proportional to the EGR activity before supplementation and only three individuals of those who completed the experiment showed results that differed from those given in Table 2. Two of these were children with high basic EGR activities and low activation coefficients before supplementation, and it was probable that they were not deficient in riboflavin at the start. The third person was one of the parents whose initial basic EGR activity was low ( 9.6 units) but whose activation coefficient indicated no ariboflavinosis $(\alpha=1 \cdot 05)$. On supplementation, however, the basic EGR activity only increased by 0.4 activity units but the activation cocfficient increascd to $\mathrm{I} \cdot 24$. It is possible that there may have been a technical error in the assay and this would partly explain the results; alternatively he may not have taken the tablets as he reported. The mean stimulation of the basic EGR activity in response to the riboflavin supplement of the G-6-PD-normal parents was $67 \pm 5 \mathrm{I} \%$ and for the children in the same group it was $56 \pm 31 \%$.

The prevalence of ariboflavinosis in February 1971, as measured by the activation 
Table 2. Correlation between the degree of ariboflavinosis as measured by activation coefficient and the resultant increase in erythrocyte glutathione reductase (EGR) activity, determined in vitro, caused by riboflavin supplementation in preschool children

(Mean values and standard deviations; no. of subjects in parentheses)

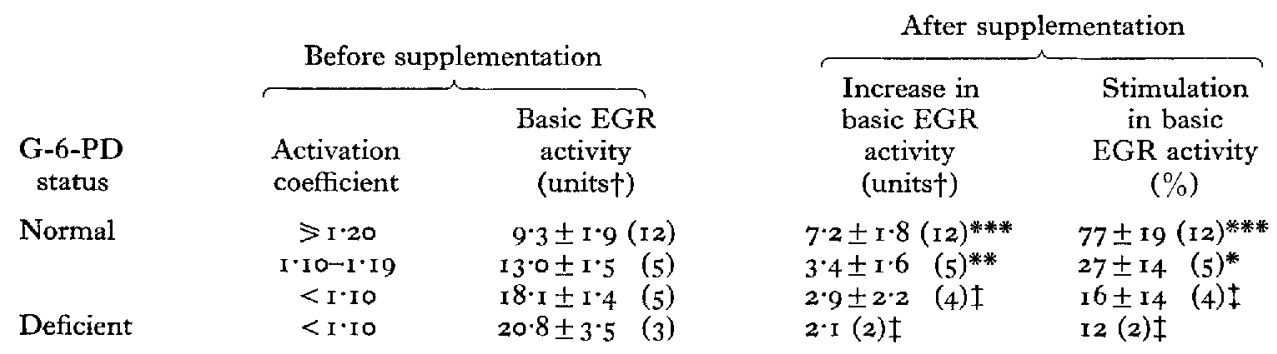

Activation coefficients were calculated by dividing the stimulated EGR (i.e. determined in the presence of added FAD) by the basic EGR.

$* P<0.01, * * P<0.005, * * * P<0.00 \mathrm{I}$, by a test for paired comparisons.

$\dagger \mu \mathrm{mol}$ reduced NADP oxidized by EGR in $\mathrm{I}$ ml erythrocytes in ro min at $35^{\circ}$.

$\ddagger$ No stimulation occurred in one child in each of these groups.

coefficient method of Glatzle et al. (I970), was $43 \%$ for the children and $39 \%$ for the parents. That is, twenty-six of the sixty children and eleven of the twenty-eight parents had activation coefficients greater than $\mathrm{I} \cdot 20$ or, alternatively expressed, had a basic EGR activity that showed an in vitro stimulation greater than $20 \%$ when FAD was added before incubation. None of the G-6-PD-deficient persons was deficient in riboflavin as assessed by this method. After the riboflavin supplementation the activation coefficients of all persons were reduced, with the exception of that of the adult mentioned above, and all fell below $\mathbf{I} \cdot 20$.

The degree of stimulation of the basic EGR values produced by the riboflavin supplement was in direct proportion to the activation coefficient of the pre-supplement samples (Table 2). Generally speaking, it was found, for both children and parents before supplementation, that those whose activation coefficient was greater than $I \cdot 20$ usually had the lowest in vitro basic EGR activities and that these subjects after receiving the riboflavin showed the greatest stimulation of the in vitro EGR activity.

\section{Dietary intake over the experimental period}

No control group was included in this study as it was considered that each group would act as its own control. However, it was found that dietary riboflavin intake had been higher in the early part of the previous year (i.e. 1970) (Thurnham, Migasena, Vudhivai et al. 197I) and that this increase in riboflavin intake corresponded to a fall in the prevalence of ariboflavinosis which occurred in March of that year in this village (Thurnham, Migasena \& Vudhivai, r97I; Thurnham, Migasena, Vudhivai t al. 1971). In view of the possibility that dictary riboflavin intake might increase during the experimental period, dietary studies on preschool children were carried out in the first $5 \mathrm{~d}$ of riboflavin supplementation. The results showed that, of the twenty children 
studied, only two received more than $0.3 \mathrm{mg} / \mathrm{Mcal}$, the highest intake being $0.35 \mathrm{mg}$. The mean dietary riboflavin intake of the group was $0.18 \pm 0.06 \mathrm{mg} / \mathrm{Mcal}$. Eleven of the children who took part in the dietary studies were in fact present in the sample group who completed the supplementation experiment. Ten of these children had normal G-6-PD values and the mean basic EGR activity of these ten children, measured before riboflavin supplementation, was compared with that of the other twelve children in the survey group whose diet was not checked during the period of supplementation. Mean values for both groups were identical (12.3 $44 \cdot 8$ and $12 \cdot 3 \pm 3 \cdot 2$ respectively), indicating that the dietary habits of the two groups of children were probably very similar.

\section{DISCUSSION}

The village where this study was made contained forty-one families and about eighty children under 8 years of age. It was expected from earlier results of Migasena, Thurnham, Jintakanon \& Pongpaew (1972), who worked in the same village on an earlier ( 1969 ) supplementation experiment with iron, that not more than $60 \%$ would take part in the experiment satisfactorily. It was decided therefore to change previous policies (Migasena, Thurnham, Pongpaew, Jintakanon \& Harinasuta, 1971) and include parents as well as preschool children in order to obtain as many subjects as possible. The subjects were not divided into control and test groups for this would have reduced the number in the experimental group. Nor was it considered practical to include another village, where the riboflavin status and dietary intakes might be different and where the villagers might not co-operate when it came to taking the second sample of blood. The study on the dietary intakes of twenty children in the village was therefore the only controlling aspect in the study to indicate what the riboflavin nutrition was like during the experimental period and what the biochemical situation may have been without the supplement. The fact that the dietary intake of riboflavin was below marginal levels (Horwitt, Harvey, Hills \& Liebert, 1950) and that the subjects were in an environment exposed to the normal stresses of life would suggest that the biochemical changes observed were due to the supplement.

It is interesting to note how low the dietary riboflavin intake of preschool children was during the supplementation period in 1971 in comparison with the values found in the previous year ('Thurnham, Migasena, Vudhivai et al. 1971). In January and April $197^{\circ}$ it was found that the riboflavin intakes were significantly higher $0 \cdot 26 \pm 0.10$ (14) $(P<0.01)$ and $0.28 \pm 0.16$ (13) mg/Mcal $(P<0.02)$ respectively than the intake in February 1971, which was $0.18 \pm 0.06$ (20) $\mathrm{mg} /$ Mcal. One observation that might account for this difference was that, in 1970 , many families had made extensive use of the recently installed irrigation system for household vegetable cultivation and vegetable intake was higher (Thurnham, Migasena, Vudhivai et al. I97I), whereas at the time of the supplementation study in $197 \mathrm{I}$ the emphasis was more on the cultivation of tobacco and 'kitchen' gardens were not as numerous.

The dose of riboflavin taken by the subjects who completed the experiment was at least $70 \mathrm{mg}$, but in most instances $90 \mathrm{mg}$, and it was taken over 7 -10 $\mathrm{d}$, according to the information collected. Various supplements of riboflavin have been used to 
stimulate EGR activity by different workers, varying from $5 \mathrm{mg}$ for $8 \mathrm{~d}$ (Beutler, I969a) to Io $\mathrm{mg}$ for $\mathrm{I} 5 \mathrm{~d}$ (Bamji \& Sharada, 1971). Horwitt et al. (1950), in one of the more intensive studies of this subject, considered that a daily supplement of $6 \mathrm{mg}$ over I $5 \mathrm{~d}$ was required to saturate riboflavin-depleted subjects. The arrangement adopted in this experiment was a compromise in which the period of supervision was reduced to ro d but the total amount taken was in most instances $90 \mathrm{mg}$, i.e. the amount recommended by Horwitt et al. (1950).

There are various modifications of the in vitro glutathione reductase test to determine riboflavin status, but they are all basically the same. The test detcrmines two things - the basic EGR activity and the degree of stimulation of this activity that can be produced by adding FAD to haemolysate before incubation. Both measurements are related to the riboflavin status of the host, but the degree of stimulation produced by the in vitro addition of FAD is considered the more useful index of riboflavin status. Beutler (I969a) and Bamji (1969) both assessed riboflavin status in terms of 'FAD effect' (or percentage stimulation) whereas Glatzle (I970) introduced the term activation coefficient and proposed the value $\mathrm{I} \cdot 20$ to separate the normal from the riboflavin-deficient subjects. Results of studies carried out in Thailand using the latter method supported this suggestion of Glatzle (Thurnham et al. 1970).

Beutler $(1969 b)$ has pointed out that alterations in the order of addition of FAD to the reagents in the in vitro test influence greatly the stimulation produced by FAD. This has been confirmed in this laboratory using the reagent concentrations of Glatzle et al. (1970), and it was found that the stimulated EGR activity could be increased such that activation coefficients were less frequently below $\mathrm{I} \cdot 00$ (unpublished observations). It has also been noticed in this department that approximately $15 \%$ of the haemolysates obtained from rural children show activation coefficients below $\mathrm{I} \cdot 00$ (cf. Thurnham et al. 1970). That is, FAD causes some inhibition of in vitro EGR activity using the method of Glatzle et al. (1970). Approximately half of these samples with activation coefficients below $\mathrm{r} \cdot 00$ are from G-6-PD-deficient subjects (unpublished results). The effect of altering the order of addition of reagents to that recommended by Beutler $(1969 b)$ was to increase the activation coefficient of all samples. To have used this modification would have necessitated establishing a new threshold to separate the nutritionally sufficient from the deficient and therefore it was not adopted in these studies. The only change made was to increase the reduced NADP concentration. It was previously found that of ten with a haemolysate of high EGR activity the oxidation of reduced NADP was not linear for the full Io min of the test. Increasing the reduced NADP concentration rectified this.

The riboflavin supplement was given to thirty-eight subjects and, with the exception of one adult male whose consumption was suspect, the results supported the generally held belief (Bamji, I969; Beutler, I969b; Glatzle et al. I970) that the EGR test is a good indication of riboflavin status. In those haemolysates in which the in vitro stimulation of EGR activity produced by FAD was less than $20 \%$ (i.e. $\alpha<\mathrm{I} \cdot 20$ ), the increase in basic EGR activity produced by the riboflavin supplement was significantly lower than in those subjects whose initial activation coefficients were greater than $\mathrm{i} \cdot \mathbf{2 0}$. That is, these results suggest that when FAD, added in vitro, produces a percentage 
stimulation of the basic EGR activity that is greater than $20 \%(\alpha>\mathbf{I} \cdot 20)$ the subject is probably riboflavin-deficient.

It is interesting to note that no ariboflavinosis could be demonstrated in the G-6PD-deficient subjects, either male or female, by this method. Flatz (1970) described an experiment in northern Thailand on G-6-PD-deficient and normal Thai people in which he gave the same riboflavin supplement and obtained results similar to those reported here. He suggested that the $\mathrm{FAD}$ might be bound more tightly to the glutathione reductase enzyme in G-6-PD-deficient persons. His values cannot be compared direct with those reported here as the conditions of assay of EGR activity were different, but the basic EGR activity of his G-6-PD-deficient subjects appeared to be stimulated by the in vivo supplement to a smaller extent than was observed in the study reported here. This difference might reflect a difference in riboflavin status, and work is in progress to determine whether the response of the basic EGR activity of G-6-PDdeficient persons to in vivo supplementation with riboflavin can be used as a method of assessing the riboflavin status of G-6-PD-deficient persons (Thurnham, 1972)

These studies were partly supported by research grants T.69-0I and T.70-05 from SEAMEO-TROPMED project. The authors are grateful to Professor B. G. Maegraith for criticizing the manuscript and to Mr P. Hongtong for technical assistance. The senior author (D. I.T.) was provided under Colombo Plan Technical Assistance to Thailand by the United Kingdom.

\section{REFERENCES}

Bamji, M. S. (1969). Clinica chim. Acta 26, 263.

Bamji, M. S. \& Sharada, D. (r97I). Clinica chim. Acta 3r, 409.

Bernstein, R. E. (1962). Nature, Land. 194, r92.

Beutler, E. (1969a). Science, N.Y. 165,613.

Beutler, E. (1969b). F. clin. Invest. $48,1957$.

Chandrapond, A. (1955). F. med. Ass. Thailand 38, I I r. (In Thai with English abstract.)

Chandrapond, A. \& Ritchie, J. (1952). \%. med. Ass. Thailand 35, I I.

Flatz, G. (1970). Nature, Lond. 226, 755.

Glatzle, D. (1970). In Proceedings of the Seventh International Congress of Clinical Chemistry Vol. 2 Clinical Enzymology p. 89 [J. Frei and M. Jemelin, editors]. Basel: Karger.

Glatzle, D., Körner, W. F., Christeller, S. \& Wiss, O. (т970). Int. Z. VitamForsch. 4o, 166.

Hauck, H. M. \& Sudsaneh, S. (x959). 7. Am. diet. Ass. 35. I 449.

Horwitt, M. K., Harvey, C. C., Hills, O. W. \& I.iebert, E. (1950). F. Nutr. 41, 247.

Interdepartmental Committee on Nutrition for National Defense (196z). Nutrition Survey: The Kingdom of Thailand. Washington, DC: US Government Printing Office.

Migasena, P., Thurnham, D. I., Pongpaew, P., Jintakanon, K. \& Harinasuta, C. (1971). In Ist Southeast Asian Regional Seminar on Nutrition, I969, Djakarta. Bangkok: SEAMEO Office. (In the Press.)

Migasena, P., 'Thurnham, D. I., Jintakanon, K. \& Pongpaew, P. (I972). Southeast Asian \%. trop. Med. publ. Illth. (In the Press.)

Thurnham, D. I. (1972). Ann. trop. Med. Parasit. (In the Press.)

Thurnham, D. I., Migasena, P. \& Pavapootanon, N. (1970). Mikrochim. Acta 5, 988.

Thurnham, D. I., Migasena, P. \& Vudhivai, N. (I97 I). Southeast Asian\%. trop. Med. publ. Hlth $2,259$.

Thurnham, D. I., Migasena, P., Vudhivai, N. \& Supawan, V. (1971). Southeast Asian Ұ. trop. Med. publ. Flth 2, 552 . 